\title{
ANALISIS POTENSI RISIKO POSTUR KERJA PEMBATIK PADA UMKM MURIA BATIK KUDUS
}

\author{
Mia Ajeng Alifiana ${ }^{1 *}$, Akh. Sokhibi², Dina Lusianti ${ }^{3}$ \\ 1,3 Program Studi Manajemen Universitas Muria Kudus, \\ ${ }^{2}$ Program Studi Teknik Industri Universitas Muria Kudus \\ *email: mia.ajeng@umk.ac.id
}

\begin{abstract}
One of the non-object cultural heritages owned by the Indonesian people is batik. Batik is a typical Indonesian cloth spread throughout the archipelago. The process of making batik is mostly still traditional, starting from the process of making patterns on the mori cloth to the process of preparing the cloth, giving patterns, nglowong / canting, isen-isen, nembok, first coloring / medel, ngerok, mbironi stage, second coloring / greeting , nglorod and washing batik. In this batik-making process, the batik workers work continuously with a detailed type of work and the work posture of the batik is on a chair that is not designed with the dimensions of the body of the batik maker. This is if the work posture is not improved, it creates a potential risk of muscle fatigue or musculoskeletal disorder. The method used in this research is quantative. The data taken in this study is the data on the size of the batik work posture when sitting on a chair. Then the data is analyzed using the REBA (Rapid Entire Body Assessment) method using ergofellow software to determine the risk of work posture. The result of this research is the potential risk of the work position of Muria Batik Kudus UMKM batik makers with the REBA method resulting in a score of 9 (Nine), which means that they have risk criteria at a high level. The potential risk that is at a high level should immediately improve the work posture of the batik which is supported by changes in work facilities. Batik makers who have the potential for high levels of risk can result in muscle fatigue in certain parts of the body and decreased levels of productivity.
\end{abstract}

Keywords: Posisi kerja, Potensi Risiko, REBA

\section{Pendahuluan}

Batik merupakan salah satu warisan budaya non benda. Salah satu ciri khas dari batik yaitu keunikannya yang memiliki makna tersendiri dari motif yang diciptakan. Menurut Asti Mdan Ambar Barini (2011) berdasarkan etimologi dan terminologinya, batik berasal dari kata mbat dan tik. Mbat merupakan bahasa Jawa yang artinya ngembat (melempar terus menerus), dan tik merupakan kata titik. Sehingga, membatik berari melempar titik terus menerus pada kain berkalikali.

Proses pembuatan batik umumnya lebih banyak dilakukan oleh UMKM-UMKM batik yang tersebar di sentra-sentra batik Indonesia, seperti Pekalongan, Yogyakarta, Surakarta, Madura, Kudus, Lasem dan lain-lain. Proses pembuatannya masih banyak dilakukan dengan cara sederhana dan kurang memperhatikan fasilitas kerja yang dapat mendukung kenyamanan pembatik. Sebagai contoh adalah fasilitas kerja berupa kursi pembatik yang tidak memenuhi aspek ergonomi. Dilihat dari aspek ergonomi, jika pembatik duduk pada kursi pembatik dalam waktu yang lama dan terus menerus, maka dapat menimbulkan pontensi risiko gangguan berupa kelelahan otot musculoskeletal disorder. Tawarka (2015) mengatakan bahwa keluhan musculoskeletal disorders (MSDs) ialah keluhan yang dirasakan dibagian otot rangka, akibat dari pemaksaan gerakan dan penerimaan beban berat dalam jangka waktu yang lama sehingga menyebabkan keluhan yakni dari keluhan sangat ringan hingga keluhan sangat sakit

Salah satu produsen batik di kabuapten Kudus yaitu UMKM Muria Batik Kudus. Fasilitas kerja yang terdapat pada UMKM Batik tersebut berupa kursi yang didesain tidak sesuai dengan ukuran tubuh pembatik nya. Kursi yang digunakan hanya kursi yang dijual secara umum dipasaran. Sehingga dapat menimbulkan potensi risiko terhadap kelelahan otot (Musculosceletal Disorder) dan menurunnya produktivitas. Posisi kerja pembatik pada UMKM batik tersebut dapat dilihat pada gambar 1 berikut: 


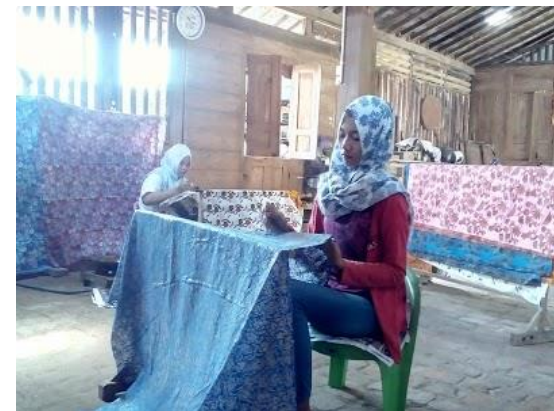

Gambar 1. Posisi Kerja pembatik Muria Batik

\section{Landasan Teori}

\subsection{Postur Kerja atau Posisi Kerja}

Postur kerja atau posisi kerja adalah bagian titik penting dalam menentukan Analisa pada keefektifan suatu pekerjaan. Hasil kerja yang baik akan diperoleh jika postur kerja yang dilakukan oleh operator memenuhi aspek ergonomis. Sebaliknya hasil kerja tidak akan baik jika operator bekerja dengan tidak memenuhi aspek ergonomis. Kelalahan yang dialami operator, maka dapat mengakibatkan produktivitas menurun dan tidak sesuai harapan. (Susihono, 2012).

\subsection{Risiko dan Manajemen Risiko}

Risiko pada dasarnya adalah ketidakpastian yang dapat menimbulkan kerugian atau kerusakan. Hal ini melekat dalam kehidupan ekonomi setiapmanusia, baik dalam kehidupan sosial maupun usaha, termasuk UMKM. Sehinggarisiko tidak dapat dihindari, tetapi dapat dikelola. Enterprise Risk Management (ERM) adalah pengelolaan risiko kredit, risiko pasar, risiko operasional, modal ekonomi dan risiko transfer dalam rangka memaksimalkan nilai perusahaan dalam kerangka yang menyeluruh dan terintegrasi (James Lam, 2007).

Penilaian risiko (risk assessment) dan mitigasi risiko (risk mitigation) merupakan intergrasi minimal dalam manajemen risiko ke dalam proses bisnis perusahaan. Untuk mencapai memperkecil risiko, maka Penilaian risiko (risk assessment) dan mitigasi risiko (risk mitigation) saling bergantung dan saling melengkapi. Di dalam risk assessment dipelajari komponen yang penting untuk merumuskan suatu risiko, antara lain karakteristik, ancaman, kelemahan sistem,kontrol, dan dampak dari terjadinya gangguan terhadap sistem. Semua komponen risiko tersebut digunakan untuk memperkirakan besarnya tingkat risiko yang mungkin terjadi, atau dengan kata lain level risiko. Sedangkan proses tindak lanjut temuan data dan rekomendasi dari proses risk assessment merupakan definisi dari risk mitigation.

\subsection{REBA atau Rapid Entire Body Assessment}

REBA ialah metode yang digunakan untuk menganalisis postur kerja operator atau pekerja. Aspek penilaian REBA pada identifikasi postur kerja operator ditempat kerja mengharuskan penilaian postur seluruh tubuh biak statis atau dinamis, perubahan postur tubuh yang terjadi secara tiba-tiba atau berubah-ubah, menambahkan ataupun tidak menambahkan beban pada saat kerja baik secara berulang-ulang atau tidak, sampai pada memodifikasi fasilitas kerja berupa alat kerja atau postur kerja yang berisiko sebelum dan sesudah dianalisis.

Postur seluruh tubuh, beban, jenis gerakan seperti tindakan, pengulangan dan genggaman adalah sata-sata yang dikumpulkan dalam analisis Penilaian REBA.

Didalam Analisis REBA ini dikelompokkan menjadi dua Grup, yaitu Grup A yang terdiri leher, pungung, kaki. Sedangkan Grup B yang terdiri dari pergelangan kedua tangan dan lengan bagian atas serta bawah

Hasil akhir dari analisis REBA ini adalah berupa identifikasi tingkatan risiko dan tindakan yang disarankan (McAtamney dan Hignett, 2000).

Adapun Kelebihan analisis REBA ini ialah sensitifitas risiko musculoskeletal pada analisis postur dari jenis-jenis pekerjaan; penilaian analisis postur tubuh dikelompokkan menjadi segmen-segmen; mengevaluasi beban dengan variabel coupling/grip; aktivitas otot yang disebabkan oleh statis, dinamis, atau postur yang berubah-ubah dilakukan dengan skoring dan tingkatan level risiko dengan perubahan yang disarankan merupakan hasil akhir dari analisis REBA ini.

Sedangkan kekurangan analisis REBA ini ialah belum adanya perhitungan lamanya waktu dan saluran; dan Hasilnya dapat kurang akurat dimana validitas dan reliabilitas nya kecil terhadap hubungan kebutuhan yang lebih khusus pada assessment ergonomi.

Hasil Analisis REBA berupa level tingkatan risiko dan perubahan yang disarankan, dimana level 1 mempunyai arti bahwa risiko tidak perlu diperhatikan dan tidak ada saran perbaikan; level 2-3 mempunyai arti bahwa risiko rendah dan mungkin diperlukan tindakan; level 4-7 mempunyai arti bahwa risiko sedang dan perlu tindakan; level 8-10 mempunyai arti bahwa risiko tinggi dan tindakan secepatnya; dan level 11-15 mempuyai arti bahwa risiko begitu tinggi dan darurat dilakukan perbaikan (McAtamney, 2005). 


\section{Metode Penelitian}

Metode yang dilakukan pada penelitian ini adalah kuantatif. Data yang diambil dalam penelitian ini adalah data ukuran postur kerja pembatik pada saat duduk pada kursi. Kemudian data tersebut dianalisa dengan REBA bantuan software ergofellow untuk menentukan risiko postur kerjanya. Variabel dependen dalam penelitian ini adalah potensi risiko posisi kerja pembatik terhadap terjadinya musculoskeletal disorders yang berdampak pada produktivitas. Variabel independen dalam penelitian ini adalah atribut penilaian posisi kerja berdasar metode REBA (Rapid Entire Body Assessment). Adapaun Objek penelitian ini adalah pembatik di UMKM Alfa Shoofa Batik dan UMKM Muria Batik Kudus.

\section{Hasil dan Pembahasan}

\subsection{Data Posisi Kerja pembatik}

Data Posisi Kerja pembatik digunakan sebagai salah satu instrument apakah postur tubuh kita dalam bekerja memiliki potensi risiko terhadap musculoskeletal disorders. Adapun data posisi kerja pembatik tersebut dapat dilihat pada gambar 2 dan table 1-8 berikut:

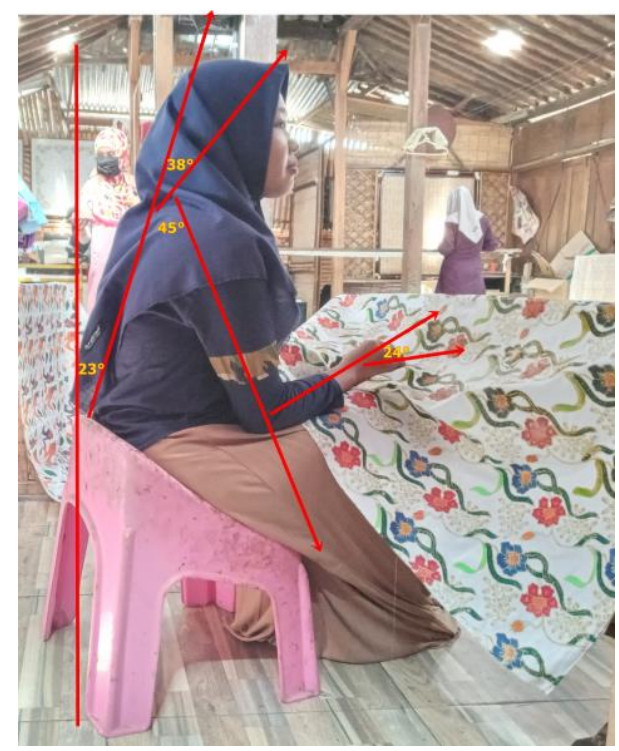

Gambar 2. Data Postur kerja pembatik Muria batik

Tabel 1. Skor Pergerakan Batang Tubuh

\begin{tabular}{lc}
\hline \multicolumn{1}{c}{ Pergerakan } & Skor \\
\hline In extension (tegak) & \\
\hline $0-20^{\circ}$ Flexion & \\
\hline$>20^{\circ}$ Flexion & $\sqrt{ }$ \\
\hline
\end{tabular}

Tabel 2. Skor Pergerakan Batang Tubuh

\begin{tabular}{ll}
\hline \multicolumn{1}{c}{ Pergerakan } & Skor \\
\hline In extension (tegak) & \\
\hline Straight (lurus) & \\
\hline $0-20^{\circ}$ Flexion & \\
\hline $20^{\circ}-60^{\circ}$ Flexion & $\sqrt{ }$ \\
\hline$>20^{\circ}$ Flexion & \\
\hline
\end{tabular}

Tabel 3. Skor Pergerakan Kaki

\begin{tabular}{lc}
\hline \multicolumn{1}{c}{ Pergerakan } & Skor \\
\hline Topang di dua kaki, & $\sqrt{ }$ \\
berjalan atau duduk & (Kaki \\
& Menekuk > \\
& $\left.60^{\circ}\right)$ \\
\hline Topang satu kaki & \\
\hline
\end{tabular}

Tabel 4. Skor beban

\begin{tabular}{lc}
\hline \multicolumn{1}{c}{ Pergerakan } & Skor \\
\hline Beban $<5$ & $\sqrt{ }$ \\
\hline Beban $5-10 \mathrm{~kg}$ & \\
\hline Beban $>10 \mathrm{~kg}$ & \\
\hline
\end{tabular}

Tabel 5. Skor Lengan Atas

\begin{tabular}{ll}
\hline \multicolumn{1}{c}{ Pergerakan } & Skor \\
\hline In extension more than & \\
$20^{\circ}$ & \\
\hline$>20^{\circ}$ extension & \\
\hline $20-45^{\circ}$ flexion & $\sqrt{ }$ \\
\hline $45-90^{\circ}$ flexion & \\
\hline$>90^{\circ}$ flexion &
\end{tabular}

Tabel 6. Skor Lengan Bawah

\begin{tabular}{lc}
\hline \multicolumn{1}{c}{ Pergerakan } & Skor \\
\hline $60-100^{\circ}$ flexion & \\
\hline $0^{\circ}-60^{\circ}$ flexion atau $>$ & $\sqrt{ }$ \\
$100^{\circ}$ flexion & \\
\hline
\end{tabular}

Tabel 7. Skor Pergerakan Pergelangan Tangan

\begin{tabular}{ll}
\hline \multicolumn{1}{c}{ Pergerakan } & Skor \\
\hline $\begin{array}{l}\text { Antara } 15^{\circ} \text { ke atas } \\
\text { dan } 15^{\circ} \text { ke bawah }\end{array}$ \\
\hline$>15^{\circ}$ ke atas dan $15^{\circ}$ & $\sqrt{ }$ \\
ke bawah & \\
\hline
\end{tabular}

Tabel 8. Skor Coupling

\begin{tabular}{lc}
\hline \multicolumn{1}{c}{ Pergerakan } & Skor \\
\hline $\begin{array}{l}\text { tidak terlalu kuat } \\
\text { namun genggaman pas }\end{array}$ & \\
\hline $\begin{array}{l}\text { genggaman bisa } \\
\text { diterima namun tidak }\end{array}$ & $\sqrt{ }$ \\
\hline
\end{tabular}


ideal

\subsection{Analisis REBA}

Data posisi kerja pembatik dilakukan analisis dengan metode REBA menggunakan software ergofellow. Gambar-gambar berikut ini merupakan hasil analisis REBA posisi kerja pembatik.

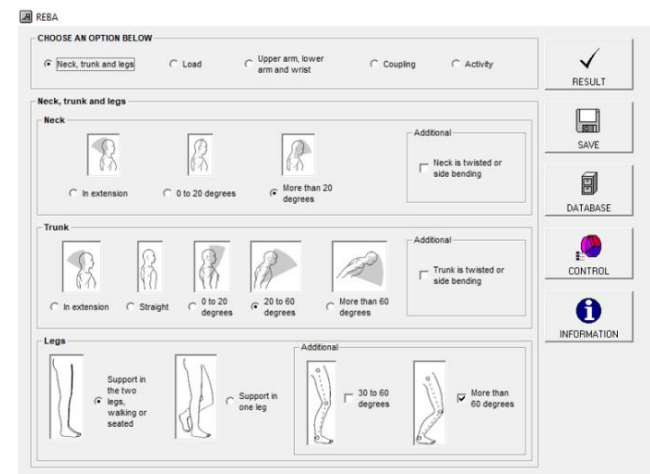

Gambar 2. REBA Pergerakan Leher, Batang Tubuh Dan Kaki Beban Yang Dibawa Pembatik

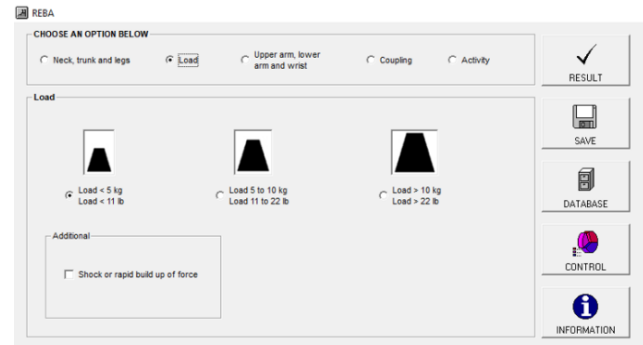

Gambar 3. REBA Beban Yang Dibawa Pembatik Postur Lengan Atas, Lengan Bawah Dan Pergelangan Tangan

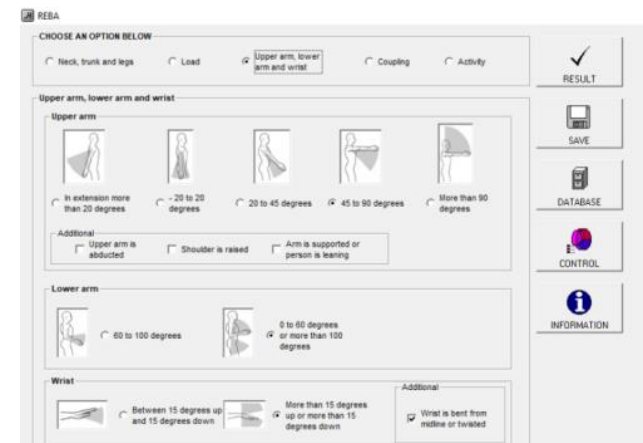

Gambar 4. REBA Lengan Atas, Lengan Bawah Dan Pergelangan Tangan

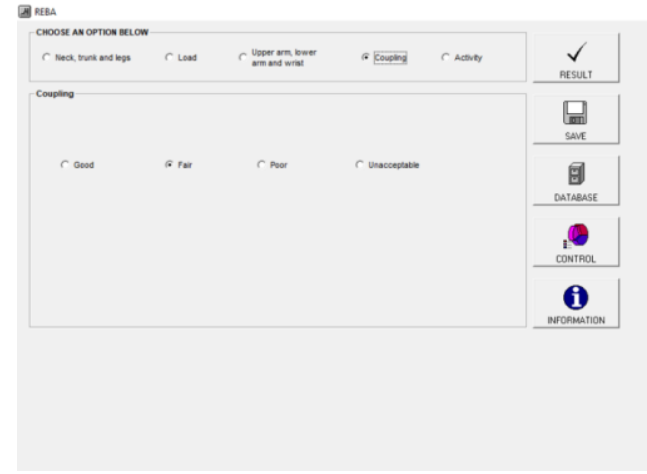

Gambar 5. REBA Coupling

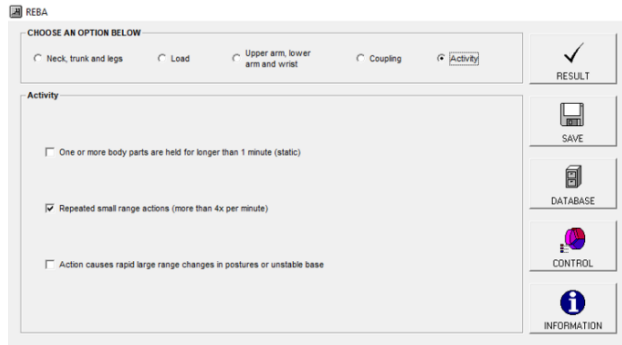

Gambar 6. REBA Aktivitas

Kesimpulan analisis REBA Posisi Kerja pembatik Muria Batik Kudus adalah sebagai berikut:

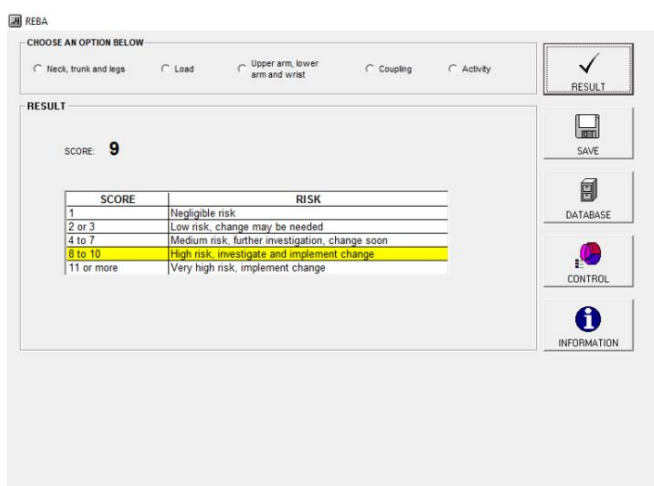

Gambar 7. Hasil REBA

Dari gambar gambar diatas dapat disimpulkan posisi kerja pembatik UMKM Muria Batik Kudus setelah dilakukan analisis menggunakan metode REBA mendapat hasil skor 9. Adapun Skor 9 tersebut berada pada level skor 8-10. Yang mana hal ini berarti bahwa pembatik Muria Batik Kudus memiliki potensi risiko tinggi, yaitu perlu tindakan. tindakan secepatnya pada posisi kerja. 


\subsection{Pembahasan}

Kriteria potensi risiko yang digunakan dalam penelitian ini adalah kuantitatif. Untuk kriteria potensi risiko kuantitatif posisi kerja pembatik berdasarkan skor potensi risiko yang terdapat pada metode REBA.

Tabel 10. Kriteria Potensi Risiko Kuantitatif

\begin{tabular}{lc}
\hline \multicolumn{1}{c}{ Level } & $\begin{array}{c}\text { Kriteria } \\
\text { Kuantitatif }\end{array}$ \\
\hline Rendah Sekali & 1 \\
\hline Rendah & $2-3$ \\
\hline Sedang & $4-7$ \\
\hline Tinggi & $10-0$ \\
\hline Tinggi Sekali & $>11$ \\
\hline
\end{tabular}

Berdasarkan tabel 10 diatas, maka dapat diketahui potensi risiko kuantitatif pada UMKM Muria Batik sebagai berikut:

Tabel 11. Potensi Risiko Kuantitatif Pada UKM Batik Alfa Shofa Dan Muria Batik.

\begin{tabular}{ccccccc}
\hline UMKM & Skor & \multicolumn{5}{c}{ Level Risiko } \\
\cline { 3 - 7 } Batik & REBA & RS & R & S & T & TS \\
\hline Muria & 9 & & & & $\sqrt{ }$ & \\
Batik & & & & & & \\
\hline
\end{tabular}

Keterangan

$\begin{array}{ll}\mathrm{RS} & \text { : Rendah Sekali } \\ \mathrm{R} & \text { : Rendah } \\ \mathrm{S} & \text { : Sedang } \\ \mathrm{T} & \text { : Tinggi } \\ \mathrm{TS} & \text { : Tinggi Sekali }\end{array}$

Dari table 11 diatas, potensi risiko posisi kerja pada pembatik UMKM Muria Batik Kudus berada pada level tinggi dengan skor 9. Sehingga harus segera mungkin dilakukan perbaikan pada posisi kerja nya dengan merubah fasilitas kerja yang lebih ergonomi berupa kursi batik yang didesain secara ergonomi.

\section{Kesimpulan dan Saran}

Potensi risiko posisi kerja pembatik UMKM Muria Batik Kudus dengan metode REBA dihasilkan skor 9. Dari skor Sembilan itu di korelasi ke kriteria risiko yang telah ditentukan berada pada level tinggi. Potensi risiko yang berada pada level tinggi harus dilakukan segera mungkin untuk perbaikan postur kerja pembatik yang didukung dengan perubahan fasilitas kerjanya.
Pembatik yang memiliki potensi risiko level tinggi dapat berakibat mengalami kelelahan otot pada bagian tubuh tertentu dan menurunnya tingkat produktivitas, sehingga disarankan melakukan perbaikan fasilitas kerja berupa kursi ergonomic bagi pembatik.

\section{Daftar Referensi}

Asti, Musman \& Arini B,Ambar. (2011). Warisan

Adiluhung Nusantara. Yogyakarta: ANDI

Hignett, S., \& Mcatamney, L. (2000). Rapid Entire Body Assessment (Reba). Applied Ergonomics, 31(2), 201-205

Lam, James. 2003. Enterprise Risk Management: From Incentives To Controls. John Willey \& Sons, Inc., New Jersey.

McAtamney, Lin. and Hignett. Sue. 2005. Rapid entire body assessment In Neville Stanton. et ai Handbook of human Faktors and ergonomis method USA : CRC Press.

Susihono Wahyu, Prasetyo Wahyu. 2012. Perbaikan postur kerja untuk mengurangi keluhan Muskuloskeletal dengan pendekatan metode Owas. Ciregon: Universitas Sultan Ageng Tirtayasa Jurusan Teknik Industri Fakultas Teknik.

Tarwaka. 2015. Ergonomi Industri Dasar dasar Pengetahuan Ergonomi dan Aplikasi di Tempat Kerja. Surakarta: Harapan Press 